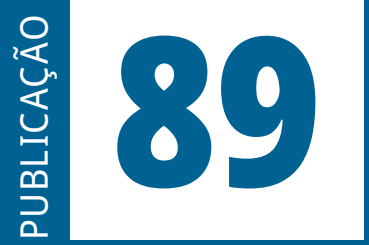

ISSN: 0101-9562

ISSN ELETRÔNICO: 2177-7055

SEQÜÊNCIA

Publicação do

Estudos jurídicos

e políticos

Programa de Pós-Graduação em Direito da UFSC

VOLUME 42 - ANO 2021 
SEQUÊNCIA - ESTUDOS JURÍDICOS E POLÍTICOS é uma publicação temática e de periodicidade quadrimestral, editada pelo Programa de Pós-Graduação Stricto Sensu em Direito da Universidade Federal de Santa Catarina - UFSC.

SEQUÊNCIA - ESTUDOS JURÍDICOS E POLÍTICOS is a thematic publication, printed every four months, edited by the Program in law of the Federal University of Santa Catarina - UFSC.

Versão eletrônica: http://www.periodicos.ufsc.br/index.php/sequencia

A publicação é indexada nas seguintes bases de dados e diretórios/

The Publication is indexed in the following databases and directories:

Base OJS

Base PKP

CCN (Catálogo Coletivo Nacional)

Dialnet

DOAJ (Directory of Open Access Journals)

EBSCOhost

Genamics Journalseek

ICAP (Indexação Compartilhada de Artigos de Periódicos)

Latindex

LivRe!

OJS
PKP
Portal de Periódicos UFSC
Portal do SEER
ProQuest
SciELO
Sherpa/Romeo
Sumarios.org
ULRICH'S
vLex

Ficha catalográfica

Seqüência: Estudos jurídicos e políticos. Universidade Federal de Santa Catarina.

Programa de Pós-Graduação em Direito. n.1 (janeiro 1980)-.

Florianópolis: Fundação José Boiteux. 1980-.

Publicação contínua

Resumo em português e inglês

Versão impressa ISSN 0101-9562

Versão on-line ISSN 2177-7055

1. Ciência jurídica. 2. Teoria política. 3. Filosoia do direito. 4. Periódicos.

I. Universidade Federal de Santa Catarina. Programa de Pós-graduação em

Direito

CDU 34(05)

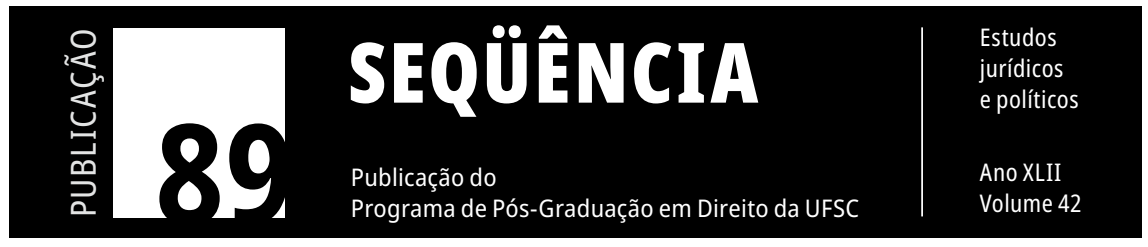




\title{
Construção do conceito de minorias e o debate teórico no campo do Direito
}

\author{
Construction of the minority concept and \\ the theoretical discussion in the Law's field
}

\author{
Barbara Lucchesi Ramacciotti ${ }^{1}$ \\ ${ }^{1}$ Centro UNIFIEO, Osasco, Brasil; \\ Universidade de Mogi das Cruzes, Mogi das Cruzes, Brasil. \\ Gerson Amauri Calgaro ${ }^{2}$ \\ ${ }^{2}$ Centro Unifieo, Osasco, Brasil.
}

RESUMO: O presente estudo caracteriza-se como pesquisa teórica original, com base em revisão bibliográfica, cujo objetivo reside em propor uma sistematização da literatura a partir da hipótese: o conceito de minorias resulta de uma construção histórico-política-filosófica-social-teórica, cujos elementos basilares derivam de pares-conceituais empregados pelas Ciências Sociais, a saber: o par-conceitual minoria-maioria (Ciência Política), o par-conceitual dominância-subjugação (Sociologia) e par-conceitual identidade-diferença (Antropologia). Chegou-se à seguinte conclusão: A revisão do debate sobre o termo minorias no campo do Direito demonstra que a hipótese proposta acima se confirma, pois possibilitou tanto sistematizar a literatura quanto compreender os principais argumentos empregados pelas diferentes vertentes analíticas.

Palavras-Chave: Minorias - Grupos Vulneráveis - Direito.

ABSTRACT: This paper is characterized as original theoretical research, based on literature review, which propose a systematization literature from the following hypothesis: the minorities concept results from a construction historical-political-philosophical-social-theoretical, which basic elements derived from conceptual-pairs used by Social Sciences, namely: the conceptual-pairs minority-majority (political science), to par-conceptual dominance-subjugation (sociology) and to 
par-conceptual identity-difference/differentiation (anthropology). The following conclusion was reached: The review of the debate on the term minorities in the field of law demonstrates that the hypothesis proposed above is confirmed, as it made it possible both to systematize the literature and to understand the main arguments used by the different analytical strands.

KEYWORDS: Minorities - Vulnerable groups - Law.

\section{INTRODUÇÃO}

Há um certo consenso entre estudiosos sobre a dificuldade de definição do conceito de minorias. O filósofo grego Aristóteles (384322 a.C.) no livro As Categorias (1973) sistematiza a primeira teoria lógico-filosófica sobre a definição de uma coisa ou de conceito a partir dos termos: espécie, gênero e diferença específica. Segundo Aristóteles, definir uma coisa significa demonstrar o que a coisa é, ou seja, demonstrar qual a sua essência. A essência das coisas ou dos indivíduos é definida por sua espécie (eidos). Assim, no caso do ser humano, cada indivíduo se define por pertencer à espécie humana. Cada espécie é definida por um gênero e por uma diferença específica. A espécie humana pertence ao gênero animal e pela diferença específica: animal racional. Em resumo: a espécie humana pode ser definida como um animal (gênero) racional (diferença específica).

Após a teoria clássica aristotélica da definição de um conceito poucas formulações surgiram, destacamos aqui a tese defendida por Deleuze e Guattari (2001) dos conceitos teóricos serem uma construção típica da filosofia. Neste artigo não vamos examinar essa tese posta pelos filósofos franceses, objeto de outro estudo ${ }^{1}$, pois nos interessa

\footnotetext{
Não examinamos aqui a tese defendida por Deleuze e Guattari em O que é a Filosofia (2001) sobre a construção de conceitos ser tarefa específica da filosofia. A construção de uma teoria para definição de conceitos ou categorias do pensamento racional tipicamente filosófico e científico tem por fundamento uma lógica. Enquanto Aristóteles sistematiza a lógica da identidade, Deleuze formula a lógica da diferença. Essa é a complexidade da
} 
aqui examinar uma hipótese mais ampla segundo a qual os termos dos vocabulários técnicos das ciências resultam de um longo processo de construção histórica, política, filosófica, social, jurídica e teórica, que sofre a influência de múltiplas variáveis e fatores.

O presente estudo pretende contribuir para o debate teórico sobre o conceito de minorias propondo uma sistematização da literatura a partir da seguinte hipótese: o conceito de minorias resulta de uma construção histórico-política-filosófica-social-teórica, cujos elementos basilares derivam respectivamente de pares-conceituais surgidos no debate filosófico empregados pelas Ciências Sociais, a saber: a Ciência Política teoriza o par-conceitual minoria-maioria, a Sociologia examina o par-conceitual dominância-subjugação (vulnerabilidade) e a Antropologia tematiza o par-conceitual identidade-diferença/ diferenciação.

Essa hipótese é corroborada, em certa medida, por Jubilut (2013) quando demonstra que o conceito de minorias possui três elementos basilares em sua construção. O primeiro elemento, reside no fato " da conceituação de minoria ser um construto histórico-político-filosófico-social" (2013, p.15). O segundo elemento: a ideia de diferenciação associada a ideia de diversidade, pois a construção do conceito de minoria implica na ideia de grupo diferente em relação à maioria da sociedade. O "terceiro elemento fundacional da temática minoritária vem a ser a ideia de subjugação, que significa a exclusão (total ou parcial) de um determinado grupo da participação ativa nas relações de poder" (2013, p.15).

Em um primeiro momento, o termo minoria foi empregado no vocabulário da Filosofia e depois pela Ciência Política a partir do contraponto entre maioria e minoria numérica na disputa pelo poder político. Posteriormente, a Sociologia utilizou o conceito de minoria para referir-se aos grupos ético-raciais em situação de não-dominância em relação à cultura e aos valores dominantes em um país. Os conceitos

construção filosófica dos conceitos. A esse respeito ver: RAMACCIOTTI (2015):

Construtivismo de Deleuze: filosofia como construção de conceitos. 
de diferença e de diversidade característicos da Antropologia Cultural como elementos constitutivos da identidade de grupos específicos passou a ser importante para a definição das minorias sociais, étnicas, linguísticas e culturais. No Brasil, os afrodescendentes, indígenas e imigrantes. Entretanto, surgiu a necessidade de ampliação do conceito de minorias para outros grupos em situação de vulnerabilidade nas sociedades modernas, tais como: crianças e adolescentes, idosos, mulheres, deficientes, população LGBTI+, moradores em situação de rua, entre outros.

A revisão do debate teórico em torno do conceito de minorias no campo do Direito demonstra que o conceito de minorias, por ser amplo, acaba implicando em ambiguidade e dificuldade para tipificar sujeitos de direito, de modo que diversos estudiosos empregam a expressão grupos vulneráveis visando conferir maior precisão ao termo minorias, procedimento relevante para a formulação de políticas públicas de proteção dos grupos minoritários.

O presente estudo caracteriza-se como uma pesquisa teórica original, que parte de revisão bibliográfica e delimita os seguintes objetivos: 1. Sistematizar o debate teórico a partir dos elementos basilares que o conceito de minorias carrega do vocabulário técnico das Ciências Sociais; 2. Fazer uma breve revisão do debate sobre o termo minorias no campo do Direito, aplicando a hipótese examinada no primeiro tópico.

\section{CONSTRUÇÃO DO CONCEITO DE MINORIA}

\subsection{0 par maioria-minoria no vocabulário da Ciência Política}

No vocabulário clássico da Filosofia Política herdado pela Ciência Política, o par maioria-minoria é definido pelo elemento numérico, significando o grupo majoritário da situação que exerce o poder de governo e o grupo minoritário, alienado do poder, tornando-se 
a oposição. O princípio da maioria é o que legitima o exercício do poder desde a definição aristotélica da democracia, como governo do povo ou de todos os cidadãos (Bоввıо, 1986, p.319).

As concepções medievais e modernas da democracia introduziram a teoria da soberania popular, que concebe o povo como a fonte originária do poder soberano, de onde deriva o princípio da maioria numérica como critério para eleições dos representantes e para as decisões de órgãos políticos supremos (BовBIo, 1986, p.327). Nas democracias representativas modernas, a maioria política é aquela que vence as eleições e seus representantes ocupam os órgãos de poder do Estado. As minorias são os que perdem e assumem a posição de oposição ao governo eleito, sendo essa dinâmica maioria-minoria ou situação-oposição central para o funcionamento pleno das democracias.

Os Estados modernos instituem os direitos civis, políticos e sociais legitimados pelo princípio da maioria, devendo esta representar, nas democracias constitucionais, os interesses e demandas do povo, ou seja, da maioria dos cidadãos. Entretanto, sabe-se que historicamente este processo não se deu sem tensões e exclusões, pois os direitos civis à liberdade e à igualdade tiveram uma instituição mais formal que de fato, ao longo dos séculos XVIII e XIX. Apenas uma minoria da população, os proprietários privados, gozavam de cidadania plena, enquanto a maioria numérica da população, os não-proprietários, ou seja, os trabalhadores assalariados (homens adultos) só conquistaram o direito ao voto a partir do século XIX. As mulheres conquistaram a cidadania política, na maioria das democracias ocidentais, somente após a Segunda Guerra Mundial.

Conforme o esquema proposto pelo sociólogo inglês T. H. Marshall no estudo clássico, "Cidadania, classe social e status" (1967), a instituição do direito e da cidadania nas sociedades modernas seguiu uma ordem cronológica e lógica, a qual mostra que os direitos não foram instituídos todos de uma vez para todos: no século XVIII surgem os direitos civis, no século XIX surgem os direitos políticos e no século XX, os direitos sociais são garantidos ao cidadão. 
A defesa de direitos civis, políticos e sociais vinculados ao conceito de cidadania foi um grande salto instituído pelas sociedades modernas. A Declaração dos Direitos do Homem e do Cidadão de 1789 foi um marco em termos do Direito Internacional, pois estabelece pela primeira vez "que os homens nascem e permanecem livres e iguais em seus direitos". A ideia da cidadania plena ganhou força no contexto dos Estados democráticos, colocando na pauta das reflexões teóricas e da prática social o problema das desigualdades e das exclusões de grande parte da população mundial, que vivia em situação de subjugação, exploração e violência, sem representação política para a conquista de seus direitos civis, políticos e sociais. (Botelho; Schwarcz, 2012; Carvalho, 2017; Rodrigues, 2010).

Portanto, verifica-se que no decorrer da formação dos Estados modernos o status de cidadão foi sendo ampliado à medida em que as massas trabalhadoras se organizavam e reivindicavam por direitos civis de fato (igualdade, liberdade para todos), políticos (participação no governo, votar e ser votado) e direitos sociais enquanto um mínimo de bem-estar social (salário digno, aposentadoria, saúde, educação, moradia, transporte, cultura etc.) para todos, sobretudo no contexto de expansão do chamado Estado Social ou do Bem-Estar Social. (Esping-Andersen, 1991; Kerstenetzky, 2012; Liberati, 2012; Ramacciotti; Bernardino, 2019).

A ampliação do uso dos termo minorias para referir-se a sujeitos ou grupos minoritários, no sentido de grupos excluídos do direito à cidadania plena, foi tonando cada vez mais visível a insuficiência do critério numérico para a distinção entre os termos minoria-maioria, posto que as minorias, muitas vezes, correspondem numericamente à maioria da população, como no caso das mulheres, dos pretos, pardos e pobres no Brasil.

[...] a luta pela cidadania juntou-se à dos direitos civis e foi embalada pelos movimentos sociais que estouravam mundo afora, a partir dos anos 1970. A ideia de cidadania parecia, então, associar-se ao exercício pleno num estado de direitos, 
e ao exercício do convívio entre iguais e em sociedade, mas também a um exercício de diferenças entre iguais. É nessa época que surgem os movimentos de minorias e uma compreensão diferente da ideia de igualdade, com diversidade. (Вотецно; Schwarcz, 2012, p.10).

O problema da sub-representação política das minorias sociais e grupos vulneráveis nas democracias representativas atuais é um problema amplamente debatido, de modo que políticas públicas específicas, tais como as políticas de cotas de participação tem sido uma das soluções propostas para minimizar esse problema de exclusão, sub-representação ou posição histórica de vulnerabilidade social, como analisa Young (2000, p.170):

Uma forma importante de promover maior inclusão de membros dos grupos sociais sub-representados se dá por meio de dispositivos políticos destinados especificamente a aumentar a representação de mulheres, pessoas da classe trabalhadora, minorias raciais ou étnicas, castas desfavorecidas etc. Assim, esquemas como cotas em listas partidárias, representação proporcional, cadeiras parlamentares reservadas e delimitação de distritos eleitorais especiais, entre outros, têm sido propostos e implementados para promover a representação de grupos.

Este mesmo problema, a saber, a falta de representatividade política das minorias sociais nas democracias e da necessidade de garantia da igualdade e do gozo de direitos fundamentais a todos cidadãos, efetivados por políticas públicas protetivas específicas para tais sujeitos vulneráveis, é objeto da análise de Hamel (2014, p. 114):

[...] o princípio da igualdade é o norte orientador da política pública, ao passo que deve favorecer a toda a comunidade, não se esquecendo do papel da democracia. Isso se faz necessário salientar, em razão de que, sem dúvida, nas sociedades contemporâneas, o chamado Estado Social passou a atender mais os interesses de determinados grupos e categorias, esquecendo-se, por assim dizer, de grupos (minorias) carentes, as quais 
são desprovidas de forças políticas e jurídicas em meio à guerra social, ficando assim, excluídas do processo democrático

\subsection{0 par dominância-subjugação no vocabulário da Sociologia}

A insuficiência do elemento numérico para o emprego do termo minoria na definição de grupos e sujeitos sociais exigiu outra construção conceitual no vocabulário da Sociologia. Conforme Chaves (1977), o termo minoria tem sido utilizado em dois sentidos: i) Significa um grupo de pessoas em uma sociedade, que se encontra numa situação de dependência ou não-dominância em relação a um outro grupo maioritário. "As minorias recebem quase sempre um tratamento discriminatório por parte da maioria", por questão de gênero, de religião, de idade, etc.; ii) "Exprime as denominadas "minorias nacionais", grupos raciais ou étnicos que, em situação de minoria, cointegram juntamente com uma maioria um determinado Estado" (1977, p.149). Como no caso de negros, pardos, indígenas, quilombolas no Brasil, entre outros grupos sociais.

Chaves enfatiza que: "a característica essencial desses grupos não se reduz a termos numéricos, e sim a certas feições estruturais básicas nas inter-relações maioria-minoria, como a relação de poder, de acordo com a qual se verifica uma superioridade da "maioria" frente a uma minoria, inferior quanto ao poder" (CHAves, 1977, p.150). Lopes (2008, p. 20) sobre esse ponto destaca: "Nesse sentido, o critério objetivo numérico pode ser insuficiente para determinar o conceito de minoria, sendo a sua exclusão social e a falta de participação nas decisões políticas o melhor critério objetivo de definição”.

A insuficiência do critério numérico fez com que vários teóricos empregassem a expressão grupos vulneráveis para definir com maior rigor a noção de minoria, pondo em relevo o elemento da não-dominância, da subjugação ou da vulnerabilidade, independente da quantidade de membros do grupo. Conforme enfatiza Wucher (2000, 
p.46): "Grupos vulneráveis podem, mas não precisam necessariamente constituir-se em grupos numericamente pequenos: mulheres, crianças e idosos podem ser considerados 'grupos vulneráveis', sem, no entanto, se constituírem em minoria”.

A mutação da conceituação do termo minoria a partir da ideia de subjugação ou vulnerabilidade foi decisiva para a formulação de princípios do Direito Internacional e para a implementação de políticas públicas protetivas. Em um primeiro momento, as chamadas minorias tradicionais (étnicas, religiosas e linguísticas) passam a ser incluídas nas políticas e direitos protetivos, como atesta a Declaração sobre os Direitos das Pessoas pertencentes a Minorias Nacionais on Étnicas, Religiosas e Linguísticas da ONU de 1992, a qual estabelece como identificadores da diversidade os critérios de: etnia, religião, língua e cultura. Em um segundo momento, a ampliação conceitual das minorias no sentido de grupos vulneráveis, permitiu incluir outros grupos em situação de subjugação, tais como: mulheres, crianças, idosos, "minorias" LGBTI+, população em situação de rua, entre outros.

Vieira Costa (2009, p. 56-7) faz uma revisão do debate sobre a busca de critérios mais claros para a definição do termo minorias e sua aproximação e distanciamento de grupos vulneráveis na seguinte passagem:

Capotorti (apud SÉGuIN, 2002, p. 11) enumera quatro traços distintivos das minorias: o numérico, o de não dominância, a cidadania e a solidariedade no interior do grupo. Esses elementos aproximam grupos vulneráveis das minorias, os dois conceitos são considerados distintos, muito embora os critérios de identificação, para Capotorti (apud Lopes, 2008, p. 20), refiram-se apenas às tradicionais minorias étnicas, linguísticas e religiosas.

Portanto, o conceito de grupos vulneráveis amplia a necessidade de proteção para todas as minorias sociais identificadas em situação de subjugação pela sociedade majoritária. O termo vulnerabilidade é ainda vago e abstrato, principalmente no campo do Direito e da filosofia 
moral, mas aplicado à temática minoritária remete para "a situação em que pessoas estão em uma posição na qual podem ser atacadas, ofendidas, feridas ou ainda, que se comparada às demais, estejam em uma posição mais fraca” (JubiLut, 2013, p. 20).

O termo minorias na atualidade possui um emprego mais alargado, "pois se percebeu que as vezes o grupo subjugado e, portanto, minoritário pode, na verdade, ser o grupo majoritário na sociedade em geral, como o caso dos negros na África do Sul" (Jubilut, 2013, p. 16). Por conseguinte, atualmente se valoriza o critério da subjugação e não o critério numérico para a conceituação de minorias.

\subsection{0 par identidade-diferença/diversidade no vocabulário da Antropologia}

A Antropologia define seu campo teórico e seu objeto próprio enquanto ciência social quando rompe com a visão etnocêntrica ${ }^{2}$ e evolucionista predominante nas primeiras teorias antropológicas do século XIX. ${ }^{3}$ No centro desse debate teórico, que opera como um divisor do campo teórico antropológico, está o par conceitual identidade-diversidade. A visão etnocêntrica, ou melhor, eurocêntrica partia da noção da identidade da cultura dos povos da Europa colonizadora como o único modelo de civilização considerado superior e evoluído em comparação às culturas diferentes dos "outros" povos colonizados, designados como: "primitivos", "inferiores", "subdesenvolvidos".

Portanto, quando os antropólogos passam a relativizar a visão eurocêntrica e a estudar e compreender a lógica interna das culturas e dos valores dos outros povos (colonizados), os conceitos da diferença,

2 “É uma visão do mundo onde o nosso próprio grupo é tomado como centro de tudo e todos os outros são pensados e sentidos através dos nossos valores, nossos modelos, nossas definições do que é a existência”. (ROCHA, 1988, p.7).

3 A primeira geração de antropólogos de meados do século XIX na Inglaterra adotou o evolucionismo como teoria de base: Sir James George Frazer e Sir Eduard B. Tylor; nos EUA - Lewis Morgan. 
da diferenciação e da diversidade além de entrar para o vocabulário técnico da antropologia, delimitam o campo teórico da Antropologia Cultural enquanto Ciência Social em distinção às outras áreas da Antropologia (Antropologia Física, Arqueologia etc.).

Os conceitos de diferença e de diversidade passam a caracterizar não apenas os estudos da Antropologia cultural, mas igualmente as pesquisas no campo da Sociologia, na medida em que as sociedades modernas, com a redução das fronteiras, por causa das novas tecnologias e da globalização, viraram cada vez mais multiculturais, multiétnicas e plurais do ponto de vista da construção da identidade e da diversidade de grupos minoritários. ${ }^{4}$

Com base neste quadro de referências, podemos compreender a relevância do terceiro elemento basilar: diferenciação-diversidade. Jubilut (2013, p.15) observa que na construção do conceito de minorias se verifica, portanto, a tendência de identificar tais grupos como "um conjunto de pessoas que possuam características que o diferenciem da sociedade em geral". A ideia de diferenciação é chave para a definição das minorias em relação ao restante da sociedade majoritária, sendo complementada pelo elemento da diversidade, pois este envolve o direito de ser diferente tanto em relação a grupos quanto em relação a indivíduos.

Esses temas e termos do vocabulário antropológico são incorporados ao debate contemporâneo sobre o multiculturalismo na interseção com o tema da defesa dos direitos à diferença, à diversidade cultural e à identidade das minorias étnicas, religiosas, linguísticas e sociais. Lopes $(2008 ; 2015)$ faz uma revisão desse amplo debate pondo em relevo a contribuição do canadense Kymlicka, que parte da ótica do multiculturalismo na defesa das minorias culturais, sem desconsiderar os direitos das minorias sociais.

4 Sobre esse tema conferir a dissertação de MIZUTANI (2012), que analisa o conceito de minoria a partir do par-conceitual identidade-diferença e suas implicações no campo do Direito à luz da Constituição brasileira de 1988 e NATA (2011) analisa o conceito de minoria à luz do par identidade-diferença cultural no contexto português. 
Kymlicka dirige sua atenção, precisamente, a esses grupos minoritários, às nações originárias, consoante com a definição tradicional de minoria da ONU, que apenas reconhece os grupos com especiais características étnicas, lingüísticas (sic.) ou religiosas como minorias. Dessa maneira, Kymlicka dedica sua Teoria do Multiculturalismo a analisar as culturas minoritárias entendidas essas apenas como nações ou povos. Não obstante o autor canadense afirme não desconhecer a existência ou a importância de outros grupos minoritários, como as mulheres, homossexuais, idosos, etc. (LOPES, 2008, p. 24).

Hamel (2014) também examina o problema do direito das minorias sociais no contexto das sociedades multiculturais da atualidade e a insuficiência de políticas públicas protetivas, além da inoperância do poder judiciário para resolver tais demandas sociais:

A interpretação do direito em sociedades atuais diz respeito, especificamente, à interpretação constitucional. Nesse contexto, em meio a um novo e contraditório aspecto da sociedade contemporânea, que agora não se constitui mais pela tradição ou convenção moral, mas pela diversidade cultural, étnica e religiosa, de grupos minoritários e de reivindicações sócio-jurídicas, cabe pesquisar a função e o alcance da interpretação constitucional realizada hoje pelo Poder Judiciário, muitas vezes ainda em moldes dogmáticos do ponto de vista da ciência do direito (hermenêutica tradicional).

\section{DEBATE SOBRE MINORIAS NO CAMPO DO DIREITO}

Uma breve revisão de documentos internacionais, que tratam da proteção dos direitos humanos, em geral, e dos direitos das minorias e grupos vulneráveis, em particular, atesta a dificuldade de uma definição única e consensual sobre a matéria em função da própria diversidade e da complexidade dos grupos identificados sob tais rubricas, pois uma definição geral simplificada poderia excluir pessoas e grupos em situação de vulnerabilidade. 
Vieira Costa (2009) faz uma revisão desses documentos internacionais que balizam o debate em torno dos novos sujeitos de direito identificados com os termos minorias e grupos vulneráveis.

A referência direta nos documentos de abrangência global a esses novos sujeitos de direito é relativamente recente. É certo que na Declaração Universal dos Direitos do Homem de 1948 apenas irá se reconhecer direitos das pessoas individuais, mas o Pacto Internacional dos Direitos Civis e Políticos de 1966 mencionará expressamente as minorias étnicas, linguísticas e religiosas. Nesse sentido, a sua proteção jurídica ocorre dentro do Estado-nação o qual integrem, por isso é possível entender a Declaração dos Direitos dos Povos de 1976 também como instrumento de reconhecimento das minorias. Mais recentemente, em 1992, a Declaração sobre os Direitos de Pessoas pertencentes a Minorias Nacionais ou Étnicas, Religiosas e Linguísticas, inspirada no artigo 27 do Pacto dos Direitos Civis e Políticos, prescreveu que os Estados signatários protegerão e fomentarão a identidade dessas minorias em seus territórios. (Vieira Costa, 2009, p.56). ${ }^{5}$

Lopes (2008) observa que a demora na regulação dos direitos das minorias após o pacto Internacional dos Direitos Civis e Políticos de 1966 "pode ser uma consequência da dificuldade em definir o termo minoria". Dois tipos de critérios foram apontados por Capotorti (membro especial da subcomissão da ONU) para definir as minorias:

a) critérios objetivos: - a existência em um Estado de um grupo de pessoas com características étnicas, religiosas ou linguísticas diferentes ou distintas do resto da população; - a diferença numérica do grupo minoritário em relação ao resto da popu-

\footnotetext{
Art. 27 - "Nos Estados em que existam minorias, religiosas ou étnicas, não se negará às pessoas que pertençam às ditas minorias o direito que lhes corresponde, em comum com os demais membros de seu grupo, a ter sua própria vida cultural, a professar e praticar sua própria religião e a empregar o seu próprio idioma" (ORGANIZAÇÕES DAS NAÇÕES UNIDAS, 1966).
} 
lação; - a posição não dominante desse grupo minoritário. b) critério subjetivo: - o desejo das minorias de preservarem os elementos particulares que as caracterizam, ou seja, a vontade comum do grupo de conservar seus rasgos distintivos. (REMILlARD, 1986 apud Lopes, 2008, p. 20).

Não obstante, a ausência de uma teoria geral ou de princípios gerais norteadores dos critérios de proteção fomenta o conflito entre distintas abordagens jurídicas, que tratam da proteção de grupos vulneráveis. Benedict Kingsbury (2001) destaca cinco abordagens: i) Direitos humanos; ii) Direito de minorias; iii) Auto-declaração; iv) Soberania; v) Povos indígenas. Faremos uma breve síntese desta revisão sistematizada por Jubilut (2013), com o objetivo de compreender os conflitos gerados entre as diversas abordagens no campo do Direito em razão da falta de uma teoria mais ampla que defina critérios consensuais para a tipificação dos grupos minoritários como sujeitos de direitos específicos.

\section{a. Direitos Humanos}

A abordagem dos direitos humanos parte dos tratados do direito internacional, tais como a Declaração Universal dos Direitos Humanos da ONU de 1948, e de Pactos Internacionais de Direitos Humanos. Tal abordagem, de acordo com Jubilut (2013, p. 24), "propõe a utilização da arquitetura e da gramática universal dos direitos humanos para a temáticas das minorias".

A expressão direitos humanos é mais usada no plano internacional para referir-se aos direitos inerentes a todo ser humano, havendo um certo consenso entre diversos autores que "a principal característica de um direito humano estaria na proteção da dignidade da pessoa humana” (Rios JúNior, 2013, p.41). A tríade de princípios consagrada pela Revolução Francesa - liberdade, igualdade e fraternidade - são os elementos que balizam o respeito e proteção à dignidade humana (Jubilut, 2013, p.22).

$\mathrm{Na}$ abordagem dos direitos humanos duas correntes se destacam:

i) a corrente universalista, cujo centro da atenção é o indivíduo; ii) a 
corrente do relativismo cultural (multiculturalismo), que considera os direitos relativos à peculiaridade de cada cultura e por isso valoriza o coletivismo, ou o direito coletivo dos grupos. A corrente universalista defende que "todas as pessoas são destinatárias das normas de direitos humanos, podendo ser por elas protegidas, sem ressalva da cultura local" (Rios Júnior, 2013, p.45). Enquanto para o relativismo cultural, "não é possível estabelecer uma moral universal que orientará um conjunto de direitos humanos a ser aplicado a qualquer sociedade" (Rios JúNior, 2013, p.45).

A corrente universalista dos direitos humanos contribui com alguns princípios para fundamentar a proteção do direito das minorias e dos grupos vulneráveis, conforme aponta Jubilut (2013): i) as ideias de igualdade e não discriminação; ii) a proteção dos direitos culturais. A utilização das ideias de igualdade e não discriminação permite a implementação de duas ações protetivas, segue a autora: a aplicação da fórmula: regra + exceção, que estabelece uma regra geral e uma exceção para proteger o grupo minoritário, objetivando implementar a ideia de equidade; Ações afirmativas para equilibrar situações desiguais, buscando o tratamento isonômico das partes. ${ }^{6}$ A proteção dos direitos culturais: valoriza a proteção do patrimônio e da identidade cultural dos indivíduos, grupos étnicos e povos como parte dos direitos humanos.

A desvantagem da utilização desses princípios da corrente universalista dos direitos humanos é que no caso de conflitos entre os membros de grupos e o indivíduo prevalece o direito do indivíduo, sendo esta abordagem insuficiente para a proteção do direito das minorias tradicionais e de outros grupos vulneráveis, cujos direitos estão fundamentados na lógica grupal e não individual, como por exemplo tribos indígenas e quilombos no Brasil.

Sobre a interseção entre o tema dos Direitos Humanos e das ações afirmativas há um amplo debate, no qual destacamos o artigo de Piovesan (2005). 


\section{b. Direitos das Minorias}

Como visto anteriormente, em face da insuficiência da perspectiva universalista dos direitos humanos para a proteção das minorias, surge no âmbito do Direito Internacional diversos tratados voltados à proteção de tais grupos, sobretudo após o fim da Segunda Guerra Mundial, quando a ONU coloca em pauta esta matéria. Wucher faz uma revisão desse debate no âmbito da Comissão de Direitos Humanos da ONU, que passou a elaborar a partir 1947 estudos para a prevenção de discriminação e proteção de minorias (2000, p.4). Em 1966, o Pacto Internacional de Direitos Civis e Políticos foi emendado com o art. 27, e o tema voltou a ser debatido na ONU (Wucher, 2000, p.5).

Em 1992, a ONU publica a Declaração sobre os Direitos de Pessoas que pertencem a Minorias Nacionais ou Étnicas ou Linguísticas, sendo este um marco importante para a conceituação das minorias, pois fixa os critérios étnicos, linguísticos, religiosos ou culturais para a identificação de tais grupos discriminados socialmente em razão de sua diferença específica. O art. 1º,1 desta Declaração afirma: “Os Estados deverão proteger a existência e a identidade nacional ou étnica, cultural, religiosa e linguística das minorias no âmbito dos seus respectivos territórios e deverão fomentar a criação das condições necessárias à promoção dessa identidade".

Apesar da importância histórica desta Declaração da ONU, a conceituação das minorias em termos de critérios étnicos, religiosos, linguísticos e culturais se mostrou na prática adequada apenas para as minorias tradicionais, sendo insuficiente para garantir a proteção de todos os grupos vulneráveis, como observa Elida Séguin (2002, p.9): "Conceituar minorias é complexo, vez que sua realidade não pode ficar restrita a critérios étnicos, religiosos, linguísticos ou culturais. Temos que sopesar sua realidade jurídica ante as conquistas modernas".

A desvantagem da abordagem do direito das minorias é que, como parte da proteção grupal, no caso de conflito de interesses prevalece o direito do grupo. Como visto acima, critica-se essa abordagem 
de viés mais multiculturalista por dar margem a violação dos direitos dos indivíduos, dentro de uma perspectiva mais universalista.

\section{c. Auto-declaração}

Tendo em vista a dificuldade de conceituação dos termos minoria e grupos vulneráveis, surge a questão: qual o melhor critério para identificar quem pertencente a um grupo minoritário? O critério da autodeterminação ou da auto-declaração do indivíduo é proposto como identificador do pertencimento a um grupo minoritário, visando ser uma alternativa em face da polêmica entre as vertentes universalistas e multiculturalista dos direitos humanos.

A Convenção no 169 da OIT (art. 1 $\left.{ }^{\circ}, 1\right)$, que aborda os direitos de indígenas e tribais, é um marco importante na adoção do critério de auto-declaração do indivíduo em termos de consciência de sua identidade grupal, como aponta o Artigo 10, 2. "A consciência de sua identidade indígena ou tribal deverá ser considerada como critério fundamental para determinar os grupos aos que se aplicam as disposições da presente Convenção".

Esse critério da auto-atribuição tem sido usado no Brasil para identificação de grupos étnicos-raciais das comunidades dos quilombos (negros e índios) ${ }^{7}$, para a identificação de negros nas políticas de cotas em concursos públicos ${ }^{8}$, entre outras outras políticas públicas afirmativas.

7 BRASIL. Decreto n. 4.887/2003, Art. 2०. "Consideram-se remanescentes das comunidades dos quilombos, para os fins desde Decreto, os grupos étnicos-raciais, segundo critérios de auto-atribuição, com trajetória histórica própria, dotados de relações territoriais específicas (...). atestada mediante auto-identificação da própria comunidade. (...)". Disponível em: < http://www.planalto.gov.br/ccivil_03/decreto/2003/d4887. htm>. Acesso em: 2 mar. 2018.

8 BRASIL. Lei no 12.990, de 9 de junho de 2014. "Reserva aos negros 20\% (vinte por cento) das vagas oferecidas nos concursos públicos para provimento de cargos efetivos e empregos públicos no âmbito da administração pública federal, das autarquias, das fundações públicas, das empresas públicas e das sociedades de economia mista controladas pela União". Disponível em: < http://www.planalto.gov.br/ccivil_03/_ato2011-2014/2014/ lei/112990.htm>. Acesso em: 20 mar. 2018. 
Apesar do critério da auto-identificação ser legitimado e adotado por várias políticas internacionais e nacionais de proteção às minorias em respeito a sua diversidade cultural, linguística, religiosa e étnica, tal critério também é problemático em razão da possibilidade de fraude, conforme observa Walter Rothenburg: "Se a auto-atribuição apresenta-se, do ponto de vista antropológico, como o mais indicado critério de reconhecimento de uma comunidade, como remanescente de quilombo, pode ser que reste ao Direito a tarefa ingrata de invalidá-lo em situação de fraude evidente”. (2010, p.459).

A avaliação da insuficiência do critério da auto-identificação levou a ajustes na formulação das políticas públicas de cotas no Brasil, como a criação de regras para a aferição da veracidade das informações prestadas por candidatos, conforme atesta a Orientação Normativa $n^{\circ}$ 3 de $1^{\text {o }}$ de agosto de 2016, que "Dispõe sobre regras de aferição da veracidade da auto-identificação prestada por candidatos negros para fins do disposto na Lei no 12.990 , de 9 de junho de 2014". 9

\section{d. Soberania e povos indígenas}

Jubilut (2013) destaca que a soberania histórica e a abordagem dos povos indígenas têm por foco os direitos dos povos indígenas, defendem a proteção dos povos que eram os habitantes tradicionais de terras ocupadas, que foram subjugados com a colonização, como no caso do Brasil e países da América Latina e das Américas em geral. Tais abordagens se aplicam apenas a grupos minoritários tradicionais, não servindo para a proteção das minorias e grupos vulneráveis em geral.

Portanto, constata-se tanto a importância do debate teórico sobre a construção e os diferentes usos do conceito de minoria quanto a relevância das análises no campo do Direito que apontam ajustes nos critérios e regras de especificação dos sujeitos de direitos. Vemos a

9 BRASIL. Lei no 12.990, de 9 de junho de 2014. Disponível em: http://pesquisa.in.gov. $\mathrm{br} / \mathrm{imprensa} / \mathrm{jsp} / \mathrm{visualiza} /$ index.jsp?jornal=1\&pagina $=54 \& d a t a=02 / 08 / 2016$. Acesso em: 20 mar. 2018. 
relevância desse debate conceitual e jurídico, como no caso da auto-identificação como regra de aferição da elegibilidade de beneficiários, para a formulação e a implementação de políticas públicas efetivas de proteção dos grupos vulneráveis. ${ }^{10}$

Neste debate que envolve minorias éticas e multiculturalismo, a contribuição de Kymlicka é de grande relevância, como já observado por Lopes (2008, p.23), pois o canadense estabelece "um elenco especial de direitos visando garantir o pleno exercício da cidadania e a inclusão na sociedade dos grupos minoritários", sobretudo o direito à soberania dos povos tradicionais em Estados multiculturais, pós-colonizações.

O autor canadense distingue, inicialmente, dois modelos de Estados multiculturais (КумLIска, 1996, p. 14):

a) o Estado multiétnico: correspondente ao Estado onde convivem várias nações devido a um processo de imigração como, por exemplo, os Estados Unidos, Canadá e Austrália. Não obstante os imigrantes não ocuparem terras natais, podem ser considerados grupos minoritários, com a condição de que se estabeleçam conjuntamente e obtenham competências de autogoverno. [...]

b) o Estado multinacional: no qual coexistem mais de uma nação devido a um processo de convivência involuntária (invasão, conquista ou cessão) ou voluntária (formação de uma federação) de diferentes povos. As minorias desse tipo de estado são basicamente nações que existiam originariamente no território do estado, passando a conviver com outras nações que chegaram posteriormente, como é o caso dos aborígines canadenses, dos índios americanos ou dos indígenas brasileiros. (Lopes, 2008, p. 23).

Do exposto, infere-se que nenhuma das abordagens no campo do Direito examinadas acima fundamenta sozinha a tipificação e a

10 Sobre o debate dos direitos dos povos indígenas enquanto minorias Cf. RODRIGUES (2015); LOPES (2014). 
proteção adequada das minorias e dos grupos vulneráveis. Neste viés, há um vigoroso debate jurídico que visa suprir as lacunas deixadas pelo termo minorias, que não possibilita uma tipificação precisa dos sujeitos de direitos em razão da própria complexidade dos grupos minoritários abrigados sob esta denominação, fato que dificulta a implementação mais eficaz das políticas públicas protetivas destinadas aos grupos vulneráveis. Faremos neste tópico uma breve revisão desse debate.

Élida Séguin, em Minorias e Grupos Vulneráveis: uma abordagem jurídica (2001) considera irrelevante a distinção entre os termos minorias e grupos vulneráveis, tendo em vista que ambos os termos rementem a grupos que sofrem discriminação e violência, necessitando de políticas protetivas.

Existe certa confusão entre minorias e grupos vulneráveis. As primeiras seriam caracterizadas por ocupar uma posição de não dominância no país onde vivem. Os grupos vulneráveis podem se constituir num grande contingente numericamente falando, como as mulheres, crianças e idosos. (...). Na prática tanto grupos vulneráveis quanto as minorias sofrem discriminação e são vítimas da intolerância, motivo que nos levou, no presente estudo, a não nos ater à diferença existente. (SÉGUIN, 2002, p.12).

Contudo, esta posição não é considerada suficiente no debate jurídico, pois Brandi e Camargo (2013), além de destacar a importância de uma maior precisão dos conceitos, empregam a taxionomia aristotélica entre gênero e espécie para diferenciar grupo vulnerável de minorias. Os autores fixam os "grupos vulneráveis" como o gênero da espécie denominada minoria. A espécie minoria se subdivide em diferentes gêneros com diferenças específicas resultando em "minorias étnicas, raciais, religiosas, sexuais, silvícolas, deficientes, mulheres, crianças, entre tantos outros traços que formam as minorias existentes nas sociedades" (2013, p. 49).

Importante observar que os "gêneros" que tipificam a espécie geral minoria nada mais são que marcadores das diferenças sociais 
empregados nas ciências sociais para classificação dos sujeitos e grupos sociais, tais como: faixa etária (criança, adolescente, jovem, idoso), etnia, gênero (mulheres, população LGBTI+), religião, entre outros

Siqueira e Castro (2017, p. 107) enfatizam a importância da distinção entre os termos minorias e grupos vulneráveis como "fator preponderante para uma real inclusão social". Para os autores, "Tem-se notado que a ausência desta distinção acarreta prejuízos tanto para as parcelas impedidas de exercer seus direitos, e indivíduos não reconhecidos como detentores de direitos, quanto à sociedade, pois esta se vê longe de ser igualitária."

Brito (2009) por sua vez também destaca a relevância da distinção entre os termos minorias e grupos vulneráveis tendo por estratégia examinar as diferenças e os traços comuns, visando uma maior eficácia na implementação de políticas públicas específicas às demandas de cada grupo minoritário, tendo por referencial o livro de Séguin (2002).

Rios Júnior (2013, p.25) observa que o fundamental é combinar vários critérios de identificação das minorias, "desde que através deles se possa aferir com o máximo de objetividade a situação de vulnerabilidade que deve ser corrigida através do tratamento jurídico adequado. E ainda destaca que: "o conceito de minorias deve se caracterizar pela sua natureza eminentemente qualitativa, ou seja, levando em consideração o aspecto que coloca o grupo ou pessoa em situação de vulnerabilidade (cultura, etnia, língua, classe social etc.)" (Rios Júnior, p.25).

Vieira Costa (2009, p.57) observa ainda que:

a linha divisória entre minorias e grupos vulneráveis é tênue, já que da perspectiva pragmática todos estão sujeitos a injustiças, em posição de inferioridade, apresentam déficit de cidadania ou, em alguns casos desconhecem seus direitos. A única diferença maior parece consistir no critério numérico, pois muitas vezes os grupos vulneráveis representam parcela substancialmente significativa de uma população, mas sujeitos aos padrões de dominação vigentes em determinada sociedade, como acontece 
com as mulheres, crianças e adolescentes, etc., que também afligem as minorias em seu sentido corrente.

Entretanto, neste debate além dos estudos que buscam maior rigor na definição dos termos minorias e grupos vulneráveis, há outras pesquisas que destacam a importância da elaboração de uma teoria geral ou pelo menos de princípios mais gerais que possibilitem a formulação de regras de aplicação universal para fundamentar a proteção das minorias e grupos vulneráveis. Esta é a posição defendida por Jubilut (2013) e por Duarte (2013), como veremos.

Jubilut (2013) examina dois princípios, que podem auxiliar na tarefa de formulação de uma teoria geral ou critérios mais universais: a proteção da dignidade humana; a maior proteção possível. O princípio da dignidade humana é bastante criticado por seu conteúdo aberto, sendo delimitado a partir dos direitos humanos. Contudo, a noção de dignidade humana é considerada um dado, podendo ser considerada um princípio fundacional para uma teoria geral de proteção às minorias.

Além disso, a ideia de dignidade humana está na base do princípio da maior proteção possível, posto que este "decorre da busca de se efetivar a dignidade humana e é transplantada para uma teoria geral de proteção das minorias e dos grupos vulneráveis a partir do direito internacional dos direitos humanos" (JubiLut, 2013, p.27). Tal princípio permite a conjunção de regras e parâmetros gerais com situações específicas, possibilitando, portanto, solucionar vários conflitos entre as diferentes abordagens, pois em havendo conflito na aplicação de regras a escolha será pautada pelo princípio da maior proteção possível.

Um outro princípio de grande relevância para uma a formulação de uma teoria sobre proteção de minorias é apresentado por Clarice Duarte (2013), a saber o princípio da igualdade material em distinção à igualdade formal. O princípio da igualdade enquanto direito fundamental costuma ser dividido em dois tipos: 1) igualdade formal (isonomia) e 2) igualdade material (equidade).

Esta distinção clássica foi estabelecida por Aristóteles. A igualdade formal entendida como iso-nomia é traduzida pela máxima: "todos 
são iguais perante a lei", posto que iso quer dizer mesma em grego e nomia derivado de lei (nomos). Já a igualdade material como equidade, desdobra-se, conforme Duarte (2013) em duas concepções distintas: i) a busca de justiça social por meio de políticas de redistribuição; ii) a efetivação do direito à diferença cultural por meio de políticas de reconhecimento.

O princípio da igualdade material é relevante para a fundamentação de uma teoria geral de proteção das minorias, posto que o princípio da igualdade formal, que sustenta as políticas públicas universalistas, ${ }^{11}$ tem se mostrado insuficiente para a proteção e garantia do direito dos grupos vulneráveis.

\section{CONCLUSÃO}

Nesta breve revisão do debate e da literatura em torno da construção do conceito de minorias demonstramos que a hipótese da pesquisa se confirma, pois verificamos como os pares-conceituais maioria-minoria, dominância-subjugação e identidade-diferença, empregados respectivamente pela Ciência política, Sociologia e Antropologia nos estudos sobre o tema minorias, operam como elementos basilares na tarefa de definição e busca de maior precisão do conceito por outros campos teóricos, sobretudo no campo do Direito.

Portanto, a hipótese dos conceitos das ciências serem uma construção histórico-filosófico-político-social-jurídico-teórica também se

\footnotetext{
11 "As políticas universalistas são aquelas que visam garantir a todos o acesso a serviços públicos na área de saúde, educação, seguridade social, mercado de trabalho etc. No caso brasileiro, temos como exemplo de políticas universalistas o Sistema Único de Saúde (SUS), a instituição de benefícios e prestações continuadas pela Lei Orgânica da Assistência Social (LOAS) e o seguro-desemprego. Já a política de saúde indigenista é exemplo de uma política destinada especificamente a um grupo vulnerável dentro da sociedade. O mesmo se diga em relação às das políticas de caráter redistributivo, como o Bolsa-Escola ou a política de reserva de cotas para negros nas universidades públicas" (DUARTE, 2013, p.34).
} 
confirma. Hipótese corroborada por Jubilut (2013) quando aponta os elementos basilares que estão sempre presentes nas definições e análises do termo minorias: o direito à diferença e à diferenciação que envolve o direito à igualdade; a vulnerabilidade derivada da posição de subjugação, que implica nos problemas do preconceito, da discriminação, da exclusão e da violência física, psicológica e simbólica sofrida pelos grupos minoritários.

No debate jurídico diversos estudos apontam que a expressão grupo vulnerável confere maior precisão que o conceito de minorias, conforme Brandi e Camargo (2013), Siqueira e Castro (2017), Brito (2009), Rios Júnior (2013) e Vieira Costa (2009). Outros princípios têm sido apontados como elementos importantes para a construção de uma teoria de proteção das minorias e grupos vulneráveis, como o princípio da dignidade humana, apontado por Jubilut (2013) e o princípio da igualdade material, destacado por Duarte (2013).

Contudo, consideramos que a construção de um conceito mais preciso de minorias ou de uma teoria geral sobre a proteção das minorias é de maior relevância no debate teórico seja no campo do Direito ou das Ciências Sociais, quando se trata de examinar ou tipificar um conjunto de direitos ou de políticas públicas voltadas à proteção dos grupos vulneráveis. Posto que no âmbito da formulação de normas protetivas voltadas às minorias busca-se atender às demandas de sujeitos de direitos, tipificados por suas identidades e diferenças específicas, tendo como critério marcadores sociais como: faixa-etária, etnia, gênero, renda, escolaridade, entre outros. Como exemplo de políticas públicas para minorias ou grupos vulneráveis no Brasil podemos destacar: Estatuto da Criança e do Adolescente, Estatuto do Idoso, Lei Maria da Penha, Lei de Cotas raciais, Programa Bolsa Família, entre outras.

A teoria aristotélica da definição empregada por Brandi e Camargo (2013) que classifica as minorias como espécie e os grupos vulneráveis como gêneros com diferenças específicas, é uma solução possível para conferir maior precisão ao conceito em pauta. Contudo, 
tal solução nada mais faz do que empregar como gênero e diferença específica os marcadores das diferenças sociais, empregados para tipificar os diferentes sujeitos sociais, como visto acima.

Neste viés, o estudo teve por objetivo propor a sistematização do debate a partir da hipótese apresentada, sem ter a pretensão de apresentar uma revisão ou catalogação completa da literatura específica, tendo em vista que o tema minorias é interdisciplinar e transversal à diversas áreas do conhecimento.

\section{REFERÊNCIAS}

ARISTÓTELES. Obras escolhidas. In Os pensadores. São Paulo: Abril Cultural, 1973.

BRANDI, Ana Carolina Dias; CAMARGO, Nilton Marcelo de. Minorias e Grupos Vulneráveis, multiculturalismo e Justiça Social: Compromisso da Constituição Federal de 1988. In: Dirceu Pereira Siqueira e Nilson Tadeu Reis Campos Silva (Orgs). 1. Ed. Birigui-SP: Boreal, 2013.

BRITO, Jaime Domingues. Minorias e Grupos Vulneráveis: Aquilatando as possíveis diferenças para os fins de implementação das Políticas Públicas. In Argumenta, Jacarezinho, n. 11, p. 95-110, 2009. Disponível em: http:// seer.uenp.edu.br/index.php/argumenta/article/view/145/145. Acesso em: 15 mar. 2019.

BOBBIO, N. (Org.). Dicionário de Política. 2 ed. Brasília: Ed. UnB, 1986. BOTELHO, André; SCHWARCZ, Lilia M. Cidadania, um projeto em construção: minorias, justiça e direitos. São Paulo: Claro enigma, 2012. CHAVES, L. G. Mendes. Minorias e seu estudo no Brasil. Revista de Ciências Sociais, Fortaleza, v. 1, n. 1, p. 149-168, 1977.

CARVALHO, José Murilo. Cidadania no Brasil. Rio de Janeiro: Civilização Brasileira, 2017.

DELEUZE, G.; GUATTARI, F. O que é a filosofia? Tradução de Bento Prado Jr. e Alberto A. Muñoz. 2 ed. Rio de Janeiro: Editora 34, 2001.

DUARTE, Clarice Seixas. Fundamentos Filosóficos da proteção às minorias. In Direito à Diferença. São Paulo: Saraiva, 2013. 
ESPING-ANDERSEN, Gosta. The Three Worlds of Welfare Capitalism. New Jersey: Princeton University Press Princeton, 1991.

HAMEL, Marcio Renan. A Interpretação do Direito em Sociedades Multiculturais e o Problema da Equalização Entre Direito Moral e Política. Direito, Estado e Sociedade, Rio de Janeiro, Programa de Pós-graduação em Direito da PUC-RJ, n.44 p. 102 a 121 jan/jun 2014. Disponível em: http://direitoestadosociedade.jur.puc-rio.br/media/44artigo5.pdf. Acesso em: 12 jan. 2019.

JUBILUT, Liliana. Itinerário para a proteção das minorias e dos grupos vulneráveis: os desafios conceituais e de estratégias de abordagem. In Direito à Diferença. São Paulo: Saraiva, 2013.

KERSTENETZKY, Celia Lessa. O Estado do Bem-Estar Social na Idade da Razão. Rio de Janeiro: Elsevier, 2012.

LIBERATI, Wilson. Políticas Públicas no Estado Constitucional. São Paulo: Atlas, 2013.

LOPES, Ana Maria. Políticas Públicas de fortalecimento dos direitos fundamentais dos indígenas: experiência neozelandesa. Espaço Jurídico Journal of Law. Chapecó, v. 15, n. 2, p. 315-336, jul./dez. 2014. Disponível em: https:// portalperiodicos.unoesc.edu.br/espacojuridico/article/view/2722/3487. Acesso em: 5 mai. 2019.

LOPES, Ana Maria D’Ávila. Proteção constitucional dos direitos fundamentais culturais das minorias sob a perspectiva do Multiculturalismo. In: Revista de Informação Legislativa, Brasília, DF: Senado Federal, v. 45, n. 177, p. 19-29, jan./ mar. 2008. Disponível em: https://www2.senado.leg. br/bdsf/bitstream/handle/id/160330/Prote\%C3\%A7\%C3\%A3o_constitucional_direitos_177.pdf?sequence=2. Acesso em: 2 mai. 2019.

LOPES, Ana Maria D’Avila. O Direito de Saída no Contexto do Multiculturalismo. Seqüência (Florianópolis), n. 71, p. 155-176, dez. 2015. Disponível em: http://dx.doi.org/10.5007/2177-7055.2015v36n71p155. Acesso: 18 de jun. 2019.

MARSHALL, Thomas H. Cidadania, classe social e status. Tradução de Merton Porto Gadelha. Rio de Janeiro: Zahar, 1967.

MEDEIROS, Nuno; DENIS, Teresa. Multiculturalidade, interculturalidade, direitos humanos e violência de género: breves notas para pensar o caso da mutilação genital feminina em Portugal e a sua abordagem. Cadernos Pagu 
(55), Campinas-SP, Núcleo de Estudos de Gênero-Pagu/Unicamp, 2019, pp. 1-21. Disponível em: https://periodicos.sbu.unicamp.br/ojs/index.php/ cadpagu/article/view/8656400/21185. Acesso em: 10 jan. 2020.

MIZUTANI, Larissa. Ser ou não ser minoria: um estudo sobre a categoria minoria e seu lugar de reconhecimento pelo Poder Judiciário brasileiro. Dissertação (Mestrado em Direito), Faculdade de Direito, Universidade de Brasília, 2012. Disponível em: https://repositorio.unb.br/ handle/10482/10906

NATA, Gil. Diferença cultural e Democracia: Identidade, cidadania e tolerância na relação entre maioria e minorias. 300p. Tese (Doutorado em Psicologia), Faculdade de Psicologia, Universidade do Porto, Portugal, 2011. Disponível em: https://books.google.com.br/books?hl=en\&lr=\&id=9zzVMfY01N8C\&oi=fnd\&pg $=\mathrm{PP} 1 \& \mathrm{dq}=$ minoria+grupos+vulner $\% \mathrm{C} 3 \% \mathrm{~A}-$ 1veis\&ots=VSrIEtf_tS\&sig=iN_L47EaSJmKfb9y3W30dUiXf5I\&redir_es$\mathrm{c}=\mathrm{y} \# \mathrm{v}=$ onepage $\& \mathrm{q}=$ minoria $\% 20$ grupos $\% 20$ vulner $\% \mathrm{C} 3 \% \mathrm{~A} 1 \mathrm{veis} \& \mathrm{f}=$ false. Acesso em 5 maio 2020.

ORGANIZAÇÃO DAS NAÇÕES UNIDAS (ONU, 1948). Declaração Universal dos Direitos Humanos. Disponível em: https://nacoesunidas. org/direitoshumanos/declaracao/. Acesso em: 7 mar. 2019.

ONU. (1966) Pacto Internacional de Direitos Civis e Políticos. Disponível em: http://www.planalto.gov.br/ccivil_03/decreto/1990-1994/d0592. htm. Acesso em: 7 mar. 2019.

PIOVESAN, Flávia. Ações Afirmativas da perspectiva dos Direitos Humanos. Cadernos de Pesquisa, v. 35, n. 124, p. 43-55, jan./abr. 2005. Disponível em: https://www.scielo.br/scielo.php?pid=S0100=15742005000100004-\&scriptsci_arttext\&tlng=pt. Acesso em: 5 maio 2020.

RAMACCIOTTI, B.L. Construtivismo de Deleuze: filosofia como construção de conceitos. In: Carvalho, M.; Fornazari, S. K.; Haddock-Lobo, R. Filosofias da Diferença. Coleção XVI Encontro ANPOF: ANPOF, p. 20-38, 2015. Disponível em: <http://www.anpof.org/portal/images/ Colecao_XVI_Encontro_ANPOF/Filosofias_da_Diferena.pdf\#page $=20>$. Acesso em: 7 mar. 2019.

RAMACCIOTTI, B. L.; BERNARDINO, Marjorie Cruz. Welfare State: an analysis on the education development indices on brazilian education system. International Journal of Innovation Education and Research. vol7.Iss3.1361. 
v.7, p.141-161, 2019. Disponível em: DOI: https://doi.org/10.31686/ijier. Vol7.Iss3.1361.

RIOS JUNIOR, Carlos Alberto. Direitos das Minorias e limites jurídicos ao poder constituinte originário. São Paulo: Edipro, 2013.

ROCHA, E.P.G. O que é etnocentrismo. São Paulo: Brasiliense, 1988.

RODRIGUES, M.A. Políticas Públicas. São Paulo: Publifolha Editora, 2010 .

RODRIGUES, Saulo Tarso. Interculturalidade, autodeterminação e cidadania dos povos indígenas. Espaço Jurídico Journal of Law. Joaçaba, v. 16, n.1, p. 41-64, jan/jun. 2015. Disponível em: https://portalperiodicos.unoesc.edu.br/espacojuridico/article/view/2089/3767. Acesso em: 5 fev. 2019. ROTHENBURG, W. Direito Constitucional. São Paulo: Verbatim, 2010. SÉGUIN, Élida. Minorias e Grupos Vulneráveis: uma abordagem jurídica. São Paulo: Forense, 2002.

SIQUEIRA, Dirceu; CASTRO, Lorenna. Minorias e grupos vulneráveis: a questão terminológica como fator preponderante para uma real inclusão social. Revista Direitos Sociais e Políticas Públicas (UNIFAFIBE). vol. 5, n. 1, 2017. Disponível em: www.unifafibe.com.br/revista/index.php/ direitos-sociais-politicas-pub/index. Acesso em: 21 fev. 2019.

VIEIRA COSTA, Rodrigo. Direitos e reconhecimento dos homossexuais no município de Fortaleza durante a gestão Fortaleza Bela 2005-2008. Espaço Jurídico Journal of Law [EJJL], 10 (1), 52-76. Disponível em: https:// portalperiodicos.unoesc.edu.br/espacojuridico/article/view/1920. Acesso em: 2 mai. 2019.

YOUNG, Iris Marion. Representação política, identidade e minorias. Lua Nova, São Paulo, 67:139-190, 2006. Disponível em: http://www.scielo.br/ pdf/ln/n67/a06n67.pdf. Acesso em: 5 jun. 2019.

WUCHER, G. Minorias: proteção internacional em prol da democracia. São Paulo: Juarez de Oliveira, 2000. 


\section{BARBARA LUCCHESI RAMACCIOTTI}

Doutora em Filosofia pela Universidade de São Paulo (USP). Professora Titular do Mestrado em Direito do Centro UNIFIEO e do Mestrado em Políticas Públicas da Universidade de Mogi das Cruzes. Editora da Revista Cadernos Espinosanos (USP).

Endereço profissional: Av. Franz Voegeli, 300 - Continental, Osasco - SP, 06020-190, Brasil.

ORCID ID: http://orcid.org/0000-0003-3798-4165

E-MAIL: barb.lucrama@hotmail.com

\section{GERSON AMAURI CALGARO}

Doutorado em Direito Civil (PhD) pela PUC/SP. Professor Titular do Programa de Mestrado em Direito do UNIFIEO, Vice Coordenador do Programa de Mestrado do Centro Universitário Fieo e Editor da Revista Direitos Humanos Fundamentais (UNIFIEO). Endereço profissional: Av. Franz Voegeli, 300 - Continental, Osasco - SP, 06020-190, Brasil.

ORCID ID: https://orcid.org/0000-0002-1767-885X

E-MAIL: gersoncalgaro@unifieo.br

Recebido: 09/04/2020

Aceito: 18/01/2022

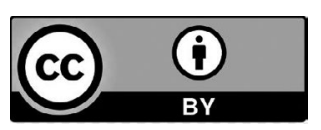

Este trabalho está licenciado sob uma licença Creative Commons Attribution 4.0 International License.

Autores e autoras cedem à Revista Sequência direitos exclusivos de primeira publicação, ficando o trabalho licenciado sob a Creative Commons Attribution 4.0 
International License. A licença autoriza que terceiros remixem, adaptem e ou criem a partir do trabalho publicado, indicando o crédito ao trabalho original e sua publicação inicial. Os autores têm permissão para assumir contratos adicionais em separado, com distribuição não exclusiva da versão publicada na Revista Sequência, indicando, de todo modo, a autoria e publicação inicial neste periódico. 